\title{
Eficiência produtiva e riscos para propriedades leiteiras: uma revisão integrativa
}

\section{Productive efficiency and risks for dairy farms: an integrative review}

Leandro Carvalho Bassotto ${ }^{1}$ (D), Marcos Aurélio Lopes $^{2}$ (D), Mozar José de Brito ${ }^{1}$ (D), Gideon Carvalho de Benedicto' ${ }^{1}$ (D)

\author{
${ }^{1}$ Programa de Pós-graduação em Administração, Universidade Federal de Lavras (UFLA), Lavras (MG), Brasil. E-mails: \\ bassotto.lc@gmail.com; mozarjdb@ufla.br; gideon.benedicto@ufla.br \\ ²Programa de Pós-graduação em Medicina Veterinária da Universidade Federal de Lavras - UFLA. E-mail: malopes@ufla.br
}

\begin{abstract}
Como citar: Bassotto, L. C., Lopes, M. A., Brito, M. J., \& Benedicto, G. C. (2022). Eficiência produtiva e riscos para propriedades leiteiras: uma revisão integrativa. Revista de Economia e Sociologia Rural, 60(4), e245277. https://doi. org/10.1590/1806-9479.2021.245277
\end{abstract}

Resumo: A eficiência operacional é fundamental para o desenvolvimento de propriedades leiteiras e está atrelada aos fatores de produção (terra, trabalho e capital). A má utilização desses recursos pode conferir mais riscos à atividade leiteira pelo possível aumento da ineficiência. Diante disso, objetivou-se analisar as relações existentes entre eficiência operacional e riscos, desenvolvendo um framework que integre diferentes pesquisas associadas ao negócio leiteiro. Foi realizada uma pesquisa qualitativa, utilizando-se a técnica de revisão integrativa da literatura em quatro artigos publicados sobre eficiência e risco na pecuária leiteira, encontrados nas bases Web of Sciece e Scopus, de 2010 a maio de 2020. Por meio do framework da gestão estratégica da eficiência e do risco, foram identificadas as principais características que compõem a eficiência de propriedades leiteiras e os riscos que podem impactá-las, bem como quais são as perspectivas futuras para o agronegócio do leite. São necessárias novas pesquisas que investiguem como os riscos advindos dos aumentos do nível de especialização, da formação profissional e da fronteira de produção podem impactar o desenvolvimento e os riscos de propriedades leiteiras. Esta pesquisa pode contribuir com o avanço do conhecimento científico acerca da eficiência e dos riscos na pecuária leiteira brasileira, bem como auxiliar produtores de leite a identificar quais são os maiores riscos da atividade.

Palavras-chave: eficiência da produção, sustentabilidade, gestão de riscos.

\begin{abstract}
The operational efficiency is essential for the development of the dairy farming, and it is connected to factor of production as land, labor, and capital. The misuse of these resources may afford risks to milk production due to the possible increase of operational inefficiency. Because of this, it was proposed to analyze the connection between operational efficiency and risks by developing a framework that composes different research associated with dairy farming. Qualitative research was carried out using the integrative literature review technique from four papers about the efficiency and risks in dairy farms from the state of Minas Gerais. These papers were found in databases Web of Science and Scopus from 2010 to 2020. Through the strategic efficiency and risk management framework, the main characteristics that make up the efficiency of dairy farms and the risks that may impact them, as well as the future prospects to the milk agribusiness, were identified. It is necessary new research that investigates how the risks that appear with the growth in the level of specialization, professional training, and the production frontier may impact the development and the risks in the dairy farms. This research contributes to the advancement of scientific knowledge about the efficiency and risks in Brazilian dairy farms and helps the milk producers to identify which are the greatest risks of milk production.
\end{abstract}

Keywords: sustainability, production frontier, risk management.

\section{Introdução}

A pecuária leiteira é um setor do agronegócio relevante para o desenvolvimento econômico e a geração de riqueza, emprego e renda para os agricultores (Fassio et al., 2005). No Brasil, segundo a Organização das Nações Unidas para a Alimentação e Agricultura (no inglês, FAO), a taxa média de crescimento da produção leiteira tem se mantido em $4 \%$ ao ano, colocando 
o país na quinta colocação no ranking dos países que mais produzem leite no mundo (Food and Agriculture Organization of the United States Nations, 2020). Segundo o Ministério da Agricultura, Pecuária e Abastecimento (MAPA), esse crescimento é notório e superior às expectativas do próprio governo federal que projeta taxa de crescimento médio da pecuária leiteira entre 2,4\% e 3,3\%, de 2015 a 2025 (Brasil, 2015). A Organização para a Cooperação e o Desenvolvimento Econômico (no inglês, OECD) aponta a elevação da produção mundial de leite (Organisation for Economic Co-operation and Development, 2018) e o potencial da produção leiteira brasileira, que se destaca pelos esforços de intensificação dos sistemas de produção e utilização de novas tecnologias de produção e informação (Ferrari \& Braga, 2021), visando à racionalização do uso de recursos produtivos e à maximização dos resultados econômicofinanceiros da atividade (Santos et al., 2020).

Contudo, a eficiência produtiva, econômica e zootécnica da pecuária leiteira de muitas propriedades ainda é baixa, reduzindo o nível de atratividade do negócio do leite (Lopes et al., 2016) e aumentando o risco de insolvência das fazendas leiteiras no longo prazo. A Teoria da Produção procura explicar a relação entre os fatores e o desempenho produtivo de propriedades leiteiras. Para tanto, essa abordagem recorre aos conceitos de produtividade e produção (Artuzo et al., 2018) para explicar as eficiências operacionais. Trata-se de uma teoria que se limita a explicar a eficiência e o uso racional dos recursos produtivos (Guo et al., 2020). Esse enfoque tem negligenciado os riscos inerentes ao processo produtivo e aqueles associados ao negócio da pecuária de leite (Gebreegziabher \& Tadesse, 2014).

As análises de risco são amplamente discutidas na literatura sobre gestão financeira, porém pesquisas que envolvem o tema análise de risco aplicadas ao agronegócio são incipientes (Dinterman et al., 2018). Estudos de risco sobre a pecuária leiteira são mais escassos e a maioria se dedica a estudá-los em empresas quando se encontram em estágios de declínio do negócio (Ogachi et al., 2020). Outras pesquisas que exploram os referidos riscos preventivamente, ou seja, antes de sua ocorrência, são igualmente escassas (Gebreegziabher \& Tadesse, 2014; Lien et al., 2017; Finger et al., 2018). Esses estudos são fundamentais para garantir que os produtores tomem decisões mais seguras e conscientes das possibilidades das condições econômicas e mercadológicas futuras.

Diversos são os tipos de riscos que afetam a atividade leiteira. Podem ser classificados em: riscos de produção, quando estão ligados ao processo produtivo; riscos de mercado, quando estão relacionados à comercialização e ao comércio exterior; ambiente e negócios, quando envolvem questões referentes a logística, infraestrutura, políticas, instituições e grupos de interesse (Arias et al., 2015). A Organização para a Cooperação e o Desenvolvimento Econômico, por outro lado, apresenta os seguintes riscos para a agropecuária brasileira: de mercado ou de preço, de produção, financeira e institucional/legal (Organisation for Economic Co-operation and Development, 2009). Esses autores demonstram a complexidade e a seriedade com que os riscos devem ser analisados no meio rural e, em especial, na pecuária leiteira. Buainain \& Silveira (2017) acrescentam, ainda, que essas categorias explicativas ajudam a compreender a forma como os riscos são considerados em processos produtivos agropecuários.

Estudos que analisem a relação existente entre eficiência e risco em propriedades leiteiras são cruciais ao desenvolvimento e fortalecimento do agronegócio leiteiro (Gebreegziabher \& Tadesse, 2014; Lien et al., 2017; Finger et al., 2018). Assim, este artigo busca a resposta à seguinte questão: quais fatores ou variáveis estão associados em pesquisas que abordam a eficiência operacional e o risco em relação ao negócio leiteiro? Este artigo visa analisar as relações existentes entre eficiência operacional e riscos desenvolvendo um framework que integre diferentes pesquisas associadas ao negócio leiteiro. 
A necessidade de ampliar estudos sobre riscos e eficiência relacionada à atividade pecuária por si só justificaria a realização desta revisão integrativa. Contudo, este artigo apresenta um framework que amplia a possibilidade de mensuração e análise da relação entre os fatores de produção e seus riscos inerentes à atividade leiteira. Em outros termos, os resultados desta revisão integrativa poderão servir de referência para o desenvolvimento de novos trabalhos sobre eficiência e riscos inerentes às atividades desenvolvidas por unidades de produção de leite.

Este artigo foi estruturado em seis tópicos, além deste introdutório. No segundo tópico, foram apresentados os principais conceitos teóricos sobre eficiência e riscos na pecuária leiteira. Posteriormente, no terceiro tópico, descreveram-se a abordagem metodológica adotada e seus desdobramentos procedimentais. No quarto tópico, foram desenvolvidas a descrição e a análise integrativa do conteúdo dos artigos selecionados que deu origem ao framework de pesquisa proposto. O quinto tópico descreve o framework de análise e sugere-se uma agenda de pesquisa. Finalmente, apontam-se as considerações finais.

\section{Fundamentação teórica}

Nos últimos anos, apesar da recessão que vem impactando o Brasil e impedido o crescimento mundial, o agronegócio brasileiro tem sido um dos principais setores da economia a se manter em crescimento, como informam o Instituto Brasileiro de Geografia e Estatística (2020) e o Centro de Estudos Avançados em Economia Aplicada (Universidade de São Paulo, 2020). Para Vilela et al. (2016), esse comportamento é notado pelas elevadas taxas de crescimento e pela capacidade de o setor suprir as demandas do mercado interno. Entre os diversos setores produtivos inseridos no agronegócio, a pecuária leiteira se destaca pela contribuição ao desenvolvimento econômico e social de agricultores que, com essa atividade, têm uma fonte de renda mais rápida no campo (Food and Agriculture Organization of the United States Nations, 2020).

Em todo o mundo, existe uma demanda pela autossuficiência de produtos de agricultura básica e, diante de sua importância econômica e social, a produção de leite se destaca pela necessidade de expansão da produção mundial (Örs \& Oğuz, 2019). Apesar de o mercado internacional do leite ser mais competitivo (Ferrari \& Braga, 2021), o Brasil ainda não consegue se destacar na exportação desse produto, fato que estimula a diminuição da atratividade do negócio no mercado interno e limita o desenvolvimento da sua cadeia produtiva (Vilela et al., 2016; Reis et al., 2020). As propriedades leiteiras tendem a ficar mais vulneráveis, uma vez que o aumento da produção nacional pode acarretar redução dos preços de venda do produto, estando a atividade mais exposta à lei da oferta e da demanda (Lien et al., 2017). Diversos autores salientam que essas consequências podem impactar significativamente o negócio do leite, uma vez que os produtores estejam mais expostos às oscilações do mercado (Gebreegziabher \& Tadesse, 2014; Sauer \& Latacz-Lohmann, 2015; Lien et al., 2017).

Segundo Perobelli et al. (2018), constata-se a predominância de pequenos e médios produtores no Brasil, fato que vem mudando nos últimos anos, uma vez que o avanço tecnológico e o aumento no volume de leite individual dessas propriedades têm contribuído com seus crescimentos. Os autores acrescentam ainda que, aliado a isso, tem-se a elevação do consumo de lácteos que pode contribuir com a melhora da qualidade do leite, sendo aspectos positivos para o fortalecimento da cadeia produtiva. Segundo Sauer \& Latacz-Lohmann (2015), todos esses fatores favorecem a competitividade da pecuária leiteira e estimulam produtores a expandir suas capacidades produtivas. 
A intensificação de sistemas de produção é vista como uma tendência global, impactando diretamente as propriedades leiteiras (Douphrate et al., 2013), que se veem cada vez mais pressionadas a elevar a eficiência produtiva para se manterem competitivas. Para que a intensificação de sistemas produtivos ocorra, é necessário que os fatores de produção (terra, trabalho e capital) sejam utilizados de modo que garantam elevados padrões de eficiência. Por serem naturais, muitos desses fatores não podem ser manipulados e suas intempéries podem impactar significativamente a atividade leiteira. Thornton et al. (2018) chamam a atenção para mudanças climáticas e pluviométricas, entre outros, que interferem na atividade leiteira. O resultado é a necessidade de mais aportes de recursos para garantir elevados índices de produtividade e diminuir os riscos do negócio a longo prazo (England et al., 2019).

Existem outros riscos que podem ser evitados ou ter seus impactos mitigados. Kivaria et al. (2006) destacam uma série de riscos advindos de problemas operacionais (problemas de qualidade, de alimentação, da água e sanitários, entre outros) e de estratégias de gestão, como as práticas de marketing, que podem interferir substancialmente na eficiência da atividade leiteira.

Propriedades leiteiras de pequeno porte, por possuírem mais limitação de recursos, são fortemente impactadas pelos riscos que podem surgir. Para Gebreegziabher \& Tadesse (2014), essas propriedades tendem a ser mais vulneráveis, uma vez que o processo produtivo é menos desenvolvido que o de propriedades de grande porte. Já em propriedades maiores, há mais disponibilidade de recursos que favorece sistemas produtivos mais eficientes (Finger et al., 2018). Contudo, o aumento da eficiência aumenta a complexidade dos riscos que podem surgir, deixando essas propriedades mais expostas a riscos com mais capacidade de danos à atividade leiteira (Evink \& Endres, 2017). Ao analisarem diferentes determinantes de risco, Finger et al. (2018) destacaram alguns tipos que podem interferir na atividade leiteira (produtividade da terra, mão de obra, alimentação, rebanho e custos). Sauer \& Latacz-Lohmann (2015) corroboram com esse entendimento e também indicam que os principais deles foram a terra, a mão de obra, a alimentação, o tamanho do rebanho e os custos de produção. Todos esses determinantes de riscos possuem relação direta com a eficiência de propriedades leiteiras.

No próximo tópico, serão apresentados procedimentos metodológicos utilizados para realizar revisão integrativa da literatura.

\section{Metodologia}

No desenvolvimento deste artigo, de natureza qualitativa, optou-se pela aplicação do método de revisão integrativa da literatura (Torraco, 2016). Esse método tem sido recomendado para a construção de agenda de pesquisa e formulação de novas abordagens teóricas, considerando o conhecimento produzido sobre temas emergentes e maduros (Torraco, 2016). As revisões integrativas permitem a elaboração de framework ou abordagens teóricas que podem compor diferentes aportes teóricos formulados por outros pesquisadores. Além de gerar uma visão integrada de diferentes teorias ou modelos de análise, esse método de revisão de literatura potencializa a geração de análises mais densas e qualificadas (Souza et al., 2010). Em síntese, esse método de revisão permite gerar um panorama mais abrangente de conceitos complexos, por meio da multiplicidade de propósitos, teorias e problemas relevantes para uma determinada área do conhecimento (Whittemore \& Knafl, 2005).

A proposta de análise de eficiência e risco fundamentou-se em uma pesquisa bibliográfica em periódicos publicados e indexados nas bases Web of Science (WoS) e Scopus. A pesquisa foi realizada entre maio e junho de 2020, tendo abordado artigos publicados entre 2010 e maio de 2020. Este foi definido para que se contemplassem apenas artigos mais recentes (últimos 
dez anos). Foram identificados e analisados quatro artigos que abordassem os temas análise de eficiência e de risco na pecuária leiteira (Quadro 1). Para isso, foram utilizados os seguintes descritores: operational, operational management, risk, risk management, milk production, dairy farms, dairy production, portfolio frontier e efficiency. Esses descritores foram pesquisados com a utilização dos operadores booleanos $A N D$ e $O R$ no título, resumo e palavras-chave dos artigos. Foram selecionados 141 artigos de todas as categorias da WoS. Posteriormente, foram mantidos todos aqueles categorizados pelas bases de dados como artigos de economia e/ou negócios. Foi realizado o mesmo procedimento na Scopuse, posteriormente, excluídas todas as duplicidades existentes, resultando em 12 artigos. Destes, foi realizada uma leitura minuciosa do resumo, metodologia e conclusões para selecionar os artigos, considerando a relevância do periódico, expressa pelo fator de impacto (sendo aceitos apenas artigos com índice superior a 1.000) e a relação entre a temática dos artigos com essa pesquisa.

Quadro 1. Artigos utilizados na análise de revisão integrativa sobre eficiência e risco na pecuária leiteira

\begin{tabular}{|c|c|c|c|c|}
\hline \multirow{2}{*}{ Item } & \multicolumn{4}{|c|}{ Artigos } \\
\hline & Um & Dois & Três & Quatro \\
\hline Autores e ano & $\begin{array}{l}\text { Sauer \& Latacz- } \\
\text { Lohmann (2015) }\end{array}$ & $\begin{array}{l}\text { Evink \& Endres } \\
\qquad(2017)\end{array}$ & Lien et al. (2017) & $\begin{array}{l}\text { Gebreegziabher \& } \\
\text { Tadesse (2014) }\end{array}$ \\
\hline Título & $\begin{array}{c}\text { Investment, } \\
\text { technical change } \\
\text { and efficiency: } \\
\text { empirical evidence } \\
\text { from German dairy } \\
\text { production }\end{array}$ & $\begin{array}{l}\text { Management, } \\
\text { operational, } \\
\text { animal health, } \\
\text { and economic } \\
\text { characteristics of } \\
\text { large dairy herds } \\
\text { in } 4 \text { states in the } \\
\text { Upper Midwest of } \\
\text { the United States }\end{array}$ & $\begin{array}{l}\text { Accounting for } \\
\text { risk in productivity } \\
\text { analysis: an } \\
\text { application to } \\
\text { Norwegian dairy } \\
\text { farming }\end{array}$ & $\begin{array}{c}\text { Risk perception } \\
\text { and management } \\
\text { in smallholder } \\
\text { dairy farming in } \\
\text { Tigray, Northern } \\
\text { Ethiopia }\end{array}$ \\
\hline Periódico & $\begin{array}{c}\text { European Review } \\
\text { of Agricultural } \\
\text { Economics }\end{array}$ & $\begin{array}{l}\text { Journal of Dairy } \\
\text { Science }\end{array}$ & $\begin{array}{l}\text { Journal of } \\
\text { Productivity } \\
\text { Analysis }\end{array}$ & $\begin{array}{l}\text { Journal of Risk } \\
\text { Research }\end{array}$ \\
\hline $\mathrm{JCR}^{1}$ & 2,419 & 3,082 & 1,603 & 1,699 \\
\hline$S J R^{2}$ & 1,250 & 1,340 & 1,800 & 1,620 \\
\hline Temática & $\begin{array}{l}\text { Análise da } \\
\text { eficiência }\end{array}$ & $\begin{array}{c}\text { Análise da } \\
\text { eficiência e risco }\end{array}$ & $\begin{array}{c}\text { Análise da } \\
\text { eficiência e risco }\end{array}$ & Análise de risco \\
\hline Tipo de dados & Secundários & Secundários & Secundários & Primários \\
\hline $\begin{array}{c}\text { Técnica de } \\
\text { análise dos dados }\end{array}$ & $\begin{array}{l}\text { Modelagem } \\
\text { econométrica }\end{array}$ & Descritiva e cluster & Regressão & Análise fatorial \\
\hline $\begin{array}{l}\text { Tamanho da } \\
\text { amostra }\end{array}$ & 2.697 & 15 & 192 & 304 \\
\hline Temporalidade & 1996 a 2010 & 2012 a 2013 & 2009 & 2011 \\
\hline $\begin{array}{c}\text { Tamanho das } \\
\text { propriedades } \\
\text { analisadas }\end{array}$ & Não especificado & $\begin{array}{l}\text { Grande, com mais } \\
\text { de } 2.500 \text { vacas }\end{array}$ & Não especificado & $\begin{array}{l}\text { Pequeno, em } \\
\text { regime de } \\
\text { agricultura familiar }\end{array}$ \\
\hline País pesquisado & Alemanha & Estados Unidos & Noruega & Etiópia \\
\hline
\end{tabular}

${ }^{1}$ Fator de impacto da Web of Science. ${ }^{2}$ Fator de impacto da Scopus. Fonte: elaborado pelos autores com base nos dados obtidos nos referidos artigos e nas bases Web of Science (2020) e Scopus (2020).

O Quadro 1 apresenta as principais informações referentes aos artigos definidos para a presente pesquisa. Após a seleção das obras, foi realizada uma análise dos artigos e elaborado um framework que melhor representa os resultados apresentados. No próximo tópico serão apresentados os resultados dessa pesquisa. 


\section{Análise integrativa sobre eficiência e risco}

\subsection{Investimento, tecnologia e eficiência na pecuária leiteira}

Sauer \& Latacz-Lohmann (2015) analisaram o desenvolvimento da pecuária leiteira na Alemanha e a relação existente entre investimentos, inovação, tecnologias e eficiência produtiva. Segundo eles, têm-se constatado aumento da especialização e da produção leiteira e redução da quantidade de propriedades leiteiras. Entre as causas, destacam-se a redução das políticas governamentais de subsídio e a alta volatilidade do preço de venda da produção leiteira (Sauer \& Latacz-Lohmann, 2015).

A produtividade e a eficiência das operações são fundamentais para garantir a atratividade do negócio do leite. Esses elementos estão, muitas vezes, atrelados ao aumento dos investimentos nas unidades produtivas, mas prejudicam os custos pela elevação das depreciações. Por isso, investimentos em comunicação (internet) são considerados uma inovação tecnológica que pode contribuir significativamente com a melhora da eficiência nas propriedades leiteiras, impactando minimamente os custos da atividade (Sauer \& Latacz-Lohmann, 2015).

A eficiência contribui com a melhoria do desenvolvimento gerencial do processo produtivo do leite. $\mathrm{O}$ aumento da produtividade de leite não é consequência da melhora da eficiência, mas da capacidade do processo de inovação dessas unidades produtivas (Sauer \& Latacz-Lohmann, 2015). A elevação da inovação faz a fronteira de produção aumentar, permitindo que mais leite seja produzido e maximizando os recursos disponíveis. Por esse motivo, o processo tecnológico deve considerar investimentos em inovação que, quando bem conduzidos, podem contribuir com a redução dos riscos da atividade no longo prazo (Sauer \& Latacz-Lohmann, 2015).

O fim do sistema de quotas do leite na União Europeia pode estar desestimulando a mudança tecnológica e a eficiência das propriedades leiteiras (Sauer \& Latacz-Lohmann, 2015). Uma vez que tais fatores estejam aumentando a fronteira de produção das propriedades leiteiras, a modificação das políticas públicas que regulamentam o sistema de quotas de produção de leite na União Europeia pode prejudicar o desenvolvimento da pecuária leiteira na Alemanha. Além disso, a inovação tecnológica é uma das grandes responsáveis pela redução da ineficiência dos processos produtivos do leite (Sauer \& Latacz-Lohmann, 2015).

O padrão de educação e a formação profissional dos gestores também se destacam como fatores estratégicos para garantir eficiência e vantagem competitiva do negócio do leite. Aquelas propriedades cujos gestores apresentaram mais nível de desenvolvimento educacional foram as que tiveram mais eficiência em seus processos produtivos (Sauer \& Latacz-Lohmann, 2015). Atrelado a isso, propriedades com maiores níveis de especialização apresentaram melhoras técnica e operacional no processo de produção do leite. Do mesmo modo, o aumento do nível de especialização contribuiu com a redução da mão de obra necessária para executar as atividades operacionais do leite (Sauer \& Latacz-Lohmann, 2015).

Como consequência, constatou-se que a melhora da eficiência aumentou a liquidez financeira das propriedades leiteiras. Tal comportamento é um reflexo da melhor utilização dos recursos produtivos explorados com efetividade. Entre esses recursos, destaca-se a utilização da terra, considerada uma das maiores oportunidades para que a fronteira de produção de propriedades leiteiras seja expandida. Em resumo, investimentos em inovação tecnológica são economicamente viáveis e podem contribuir com a melhora da eficiência e o desempenho econômico da atividade leiteira.

Com base no artigo de Sauer \& Latacz-Lohmann (2015), foi desenvolvida uma representação dos principais fatores que interferem na eficiência de propriedades leiteiras alemãs (Figura 1). 


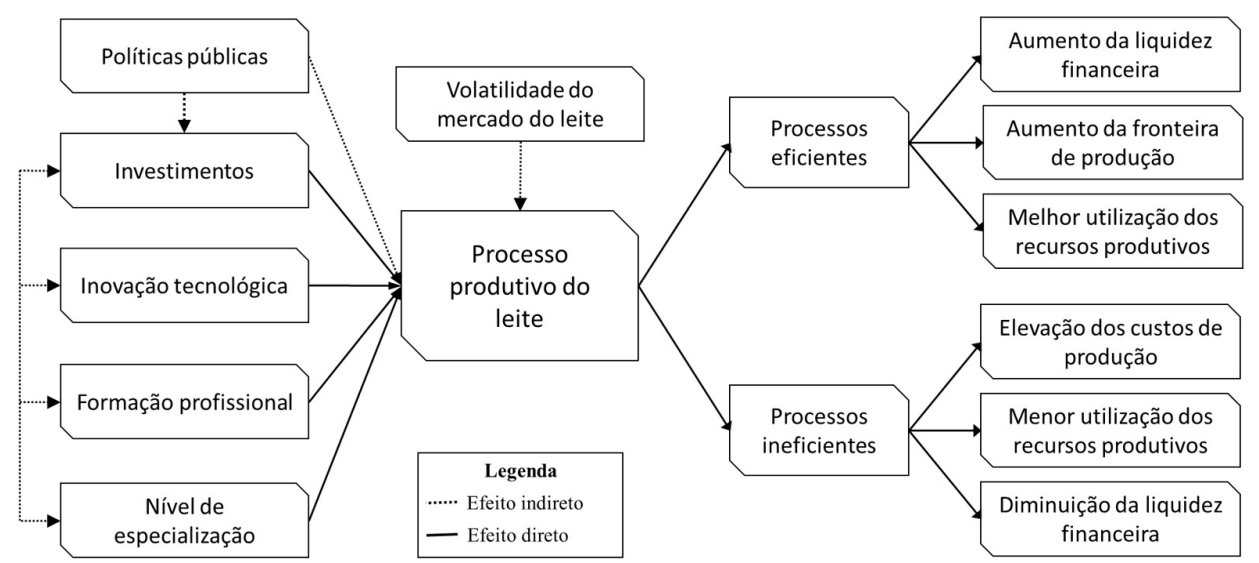

Figura 1. Fatores da eficiência produtiva de propriedades leiteiras na Alemanha. Fonte: elaborada pelos autores, segundo dados e informações de Sauer \& Latacz-Lohmann (2015).

As oscilações do preço de venda do leite são grandes e o mercado tem se mostrado mais instável com as novas políticas públicas adotadas pela União Europeia sobre o setor leiteiro (Figura 1). Foi possível constatar que elas, modificando questões relacionadas ao sistema de quotas na produção de leite, comprometem a eficiência e a capacidade de gerenciamento de investimento das propriedades alemãs. Além disso, a eficiência dessas propriedades indicou estar fortemente atrelada à capacidade de inovação tecnológica, visto que as propriedades mais eficientes foram aquelas que mais inovaram (Sauer \& Latacz-Lohmann, 2015). Do mesmo modo, a formação educacional, expressa pela formação profissional dos gestores, foi consideravelmente impactante para contribuir com a melhora do processo produtivo do leite. Também foi responsável por incrementar a elevação da especialização das propriedades, visto que, segundo os autores, melhores eficiências foram identificadas nas unidades produtivas mais especializadas na produção de leite.

A relação entre esses fatores (Figura 1) permitiu compreender que propriedades que possuem sistemas produtivos mais eficientes tendem a ter melhor liquidez financeira, visto que os custos de produção reduzem à medida que se maximiza a utilização dos recursos produtivos. Além disso, propriedades menos eficientes demonstraram ter piores resultados financeiros, advindos da elevação dos custos de produção. Nessas propriedades, os recursos produtivos não foram utilizados da melhor forma possível, motivo que justificaria a sua falta de desempenho produtivo. Segundo Sauer \& Latacz-Lohmann (2015), podem estar mais expostas a riscos por apresentarem mais grau de vulnerabilidade produtiva.

Vale salientar que as políticas públicas produzem efeitos sobre o processo produtivo do leite. Contudo, não se trata de uma influência que impacta a produção de leite de forma direta (Sauer \& Latacz-Lohmann, 2015). Destaca-se que os fatores apresentados (Figura 1) diferem quanto ao nível de influência sobre o processo produtivo e podem produzir: a) efeitos diretos decorrentes da interferência de determinados fatores (positiva ou negativamente) no processo produtivo; b) efeitos indiretos que influenciam indiretamente a atividade leiteira.

Esse artigo realizou uma pesquisa sobre a pecuária leiteira na Alemanha e permitiu compreender características de propriedades mais eficientes. Sua maior limitação foi não apresentar características mercadológicas que venham a interferir na eficiência de propriedades leiteiras alemãs (Sauer \& Latacz-Lohmann, 2015). Deste modo, pesquisas sobre o tema seriam válidas para aprofundar tais questões, visto que permitiriam uma visão mais heurística da cadeia produtiva do leite naquele país, bem como proporiam ações de estímulo à redução da taxa ou abandono da atividade leiteira no referido país. 


\subsection{Características produtivas, operacionais e econômicas de propriedades leiteiras}

O objetivo dos pesquisadores foi analisar as principais práticas de gestão, operações e sanidade animal de rebanhos leiteiros de grande porte, presentes em quatro estados norteamericanos (Evink \& Endres, 2017).

A escala de produção permite elevados padrões de eficiência econômica e produtiva na atividade leiteira (Evink \& Endres, 2017). A flutuação nos preços de commoditiese, em especial, do leite coloca as propriedades leiteiras em grande vulnerabilidade, ficando muito expostas ao mercado e aos custos de produção (Evink \& Endres, 2017). Entre os componentes dos custos de produção, a alimentação é o de mais impacto na atividade leiteira norte-americana. As unidades produtivas analisadas são altamente tecnificadas e com eficiências operacionais superiores às médias de outras propriedades leiteiras de grande porte nos Estados Unidos. A pesquisa demonstrou a importância da estrutura organizacional para o cumprimento das atividades necessárias à produção de leite, de modo que se garanta elevada eficiência gerencial nos diversos setores das propriedades (Evink \& Endres, 2017).

Embora as propriedades tenham conseguido preços do leite melhores que aqueles praticados pelo mercado norte-americano, constatou-se elevada dependência da eficiência operacional para manter a lucratividade da atividade leiteira. Os componentes dos custos de produção com maiores representatividades foram alimentação, mão de obra, reposição de animais, depreciações e remuneração do capital investido, custos elevados pelo grande investimento realizado (Evink \& Endres, 2017).

Todas as propriedades dispõem de mão de obra estrangeira para realizar as práticas operacionais não automatizadas das propriedades (Evink \& Endres, 2017). Embora haja elevada eficiência na utilização da mão de obra, os autores demonstraram ser este um risco da atividade, visto que, caso haja modificações nas políticas públicas, as propriedades poderão não conseguir contratar funcionários suficientes para realizar todas as atividades operacionais necessárias. Uma alternativa para isso, sugerida pelos autores, é intensificar tecnologias automatizadas que permitam a operacionalização com menos funcionários contratados.

Além disso, a mastite demonstrou ser um dos principais fatores que precisam ser trabalhados, visto que apresentou variação entre as propriedades analisadas. Além disso, há funcionários contratados advindos de outros países, o que demonstra a escassez de mão de obra nativa para trabalhar com pecuária leiteira (Evink \& Endres, 2017).

A Figura 2 apresenta uma síntese dos estudos propostos por Evink \& Endres (2017).

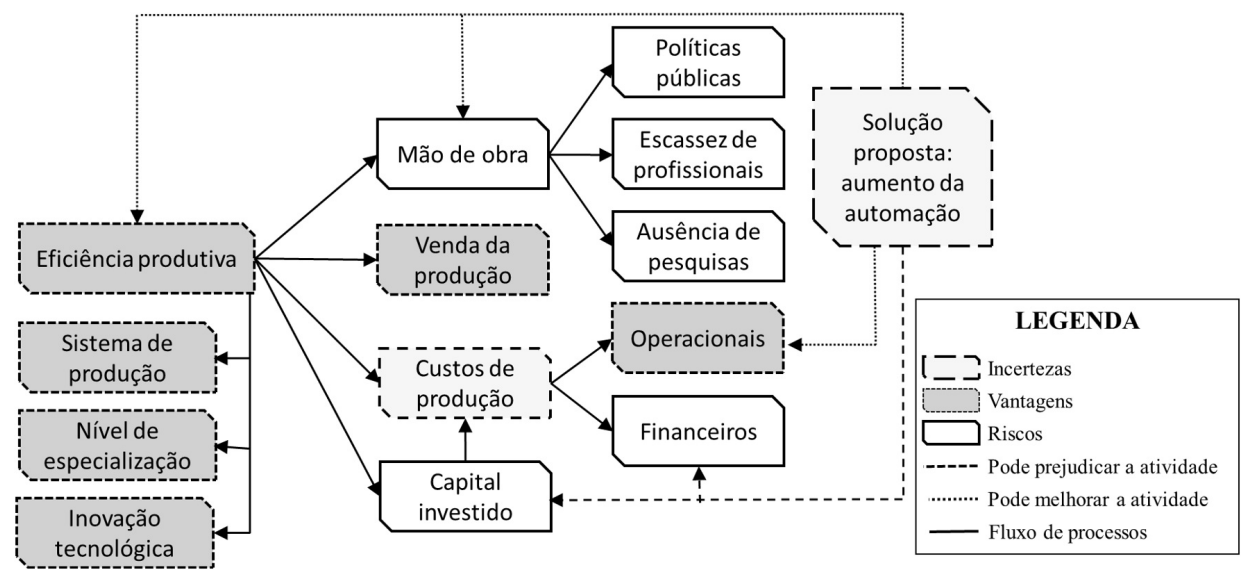

Figura 2. Fatores de eficiência em grandes propriedades leiteiras dos Estados Unidos. Fonte: elaborada pelos autores com base nos dados e informações de Evink \& Endres (2017). 
O estudo de Evink \& Endres (2017) apresentou três características que ajudam a explicar a eficiência produtiva de propriedades leiteiras (Figura 2). A primeira é a inovação tecnológica, que permite utilizar tecnologias que aumentem a automação do processo produtivo e contribuam com a elevação da qualidade e a maximização dos recursos produtivos. O nível de especialização é considerado outro fator de forte impacto na atividade, visto que propriedades que realmente não sejam especializadas na produção de leite podem ter sérios problemas de viabilidade econômica a longo prazo. O terceiro é a escolha do sistema de produção, o qual a pesquisa dos autores demonstrou sua importância para a especialização, mas não se aprofundou no tema.

Apesar de os autores terem salientado que a volatilidade dos preços do leite nos Estados Unidos é uma ameaça para o setor, parece não ser um problema relevante para as propriedades analisadas. Na maioria delas, o leite produzido foi comercializado com preços superiores aos praticados no mercado.

Existem dois riscos principais para a pecuária leiteira norte-americana: a mão de obra e o capital investido (Evink \& Endres, 2017). O primeiro fator que interfere na mão de obra corresponde às políticas públicas, com especial destaque para as de imigração, que restringem a inserção de trabalhadores de outras nacionalidades na atividade leiteira. O país carece de profissionais nativos que desenvolvam atividades operacionais em propriedades leiteiras, o que pode ser constatado pela existência de imigrantes em todas as 15 propriedades do estudo (Evink \& Endres, 2017). Além disso, os autores acrescentam que há poucas pesquisas que investigaram o impacto da escassez de mão de obra e das políticas públicas na pecuária leiteira.

Por serem de grande porte, o elevado capital investido contribui com a eficiência dessas propriedades, mas prejudica a ampliação de seus níveis de utilização de tecnologias (pois já possuem elevado desenvolvimento tecnológico). Além disso, novos investimentos demandam vultuosos aportes financeiros que aumentam o capital imobilizado e elevam os custos de produção, pelo incremento das depreciações e da remuneração do capital investido (Evink \& Endres, 2017). Como consequência, há mais incerteza sobre os custos de produção que podem não contribuir para gerar resultados positivos, visto que, dependendo do aporte investido, podem ser superiores às receitas da atividade, conferindo prejuízo aos pecuaristas.

Evink \& Endres (2017) apresentaram uma solução que poderia auxiliar nos problemas dessas propriedades leiteiras quanto à utilização de mão de obra: a elevação da automação dos processos produtivos. Tal medida reduziria os impactos negativos da escassez de profissionais para atuarem na atividade e deixaria as propriedades menos dependentes de políticas que regulamentam a imigração no país. Entretanto, o aumento da automação implica elevar substancialmente o capital investido, podendo inflar os custos e diluir os resultados da atividade. Por esse motivo, é considerada uma incerteza, visto que seu impacto no desempenho de grandes propriedades leiteiras pode desencadear efeitos colaterais prejudiciais. Ainda assim, a automação da atividade leiteira parece ser uma medida viável, visto que aumentaria o nível de especialização do processo produtivo e melhoraria a inovação tecnológica dessas propriedades, características fundamentais para a elevação da eficiência dos processos produtivos do leite nos Estados Unidos (Evink \& Endres, 2017).

Esta pesquisa apresentou uma pequena quantidade de propriedades analisadas. Tal limitação se deu pela baixa incidência de propriedades leiteiras que tenham mais de 2.500 vacas no rebanho. Por não haver estudos que investigam a eficiência de processos produtivos desse porte, a pesquisa é fundamental para ampliar o conhecimento sobre a eficiência de grandes propriedades leiteiras. 


\subsection{Análise da produtividade e do risco na pecuária leiteira}

O foco deste artigo é analisar os efeitos dos riscos sobre a gestão em propriedades leiteiras norueguesas (Lien et al., 2017). Existem inúmeros fatores que interferem na gestão dos riscos. Variáveis não controláveis (clima, mercado, riscos de poluição, entre outras) exercem forte impacto sobre a gestão e o desenvolvimento da atividade leiteira. Existe, ainda, a possibilidade de riscos provenientes das práticas gerenciais, como redução na utilização dos insumos para diminuir as despesas, impactando no volume e na qualidade do leite produzido. Outro aspecto que pode impactar a atividade leiteira é a percepção dos agricultores sobre os riscos que refletem na atividade, resultando na tomada de decisões distintas para tentar mitigar um determinado risco (Lien et al., 2017). Isso implica dizer que as diferentes estratégias adotadas pelos pecuaristas devem ser consideradas nas análises de risco, visto que podem impactar diretamente a eficiência operacional da produção de leite.

Lien et al. (2017) identificaram a existência de três índices de risco que podem interferir na eficiência produtiva do leite: a atitude para o risco, a percepção do risco e a habilidade de gerenciar riscos na atividade leiteira. Os custos da atividade são utilizados para balizar a influência de tais índices no referido processo produtivo.

A escala de produção é uma relevante prática de minimização dos riscos. Considerando o princípio ceteris paribus, o aumento da produtividade contribuiu com a redução dos custos de produção do leite. $O$ aumento nos três índices de análise (atitudes para o risco, percepção do risco e habilidade de gerenciar o risco) contribuíram com o aumento da escala de produção (Lien et al., 2017).

As propriedades que tiveram mais riscos foram aquelas que apresentaram menos produção de leite. Assim, o aumento da escala de produção contribuiu com a redução dos riscos do negócio, assim como com a redução dos custos da atividade (Lien et al., 2017). Do mesmo modo, aquelas propriedades cujos pecuaristas se mostraram mais otimistas em relação ao futuro apresentaram mais produtividade. Comportamento similar foi identificado também em relação ao nível de educação dos produtores.

A Figura 3 apresenta uma síntese dos principais fatores de eficiência e risco para a pecuária leiteira norueguesa, segundo Lien et al. (2017).

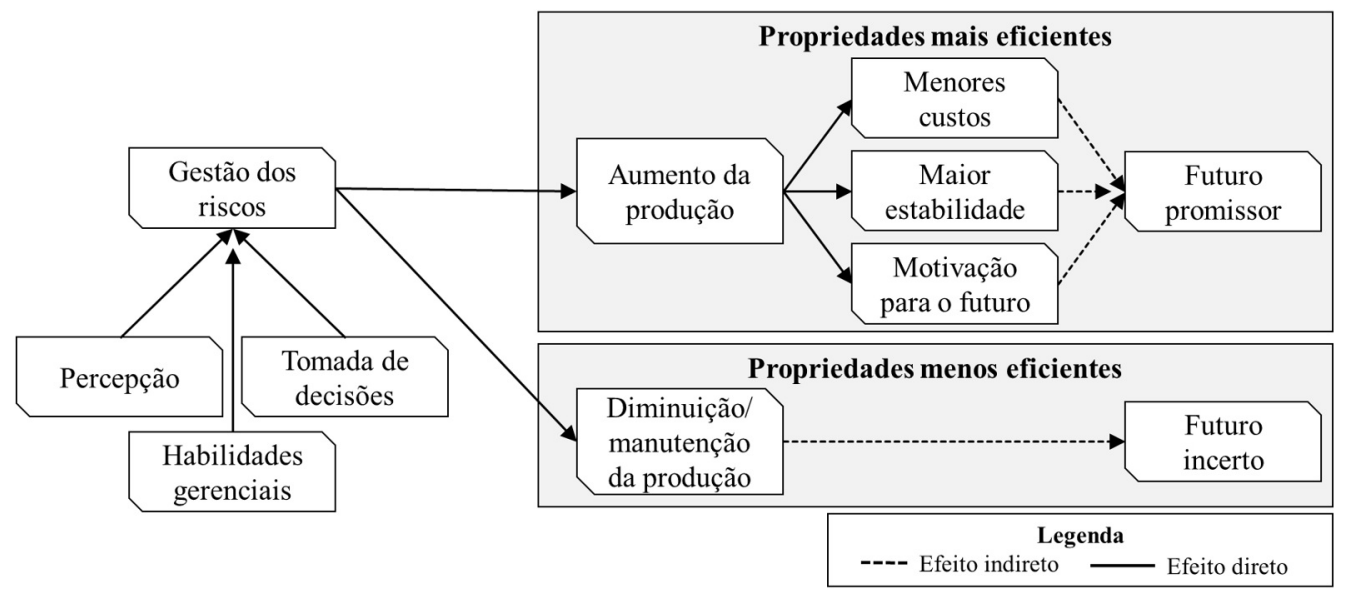

Figura 3. Fatores de eficiência e risco em propriedades leiteiras da Noruega. Fonte: elaborada pelos autores, com base nos dados e informações de Lien et al. (2017). 
A gestão dos riscos é composta de três habilidades (Figura 3). A primeira delas, a percepção, reflete a capacidade dos gestores em identificar a existência do risco ou sua iminente possibilidade. A segunda, habilidades gerenciais, são as capacidades dos gestores de conseguir gerir suas atividades e definir práticas de gestão que contribuam com a gestão de riscos. Essas duas características são complementadas pela capacidade dos gestores em tomar decisões relacionadas ao risco, visando mitigá-lo ou preveni-lo (Lien et al., 2017).

Estudos evidenciam que existem propriedades com mais e menos capacidade de gerir os riscos. As mais eficientes foram aquelas que conseguiram produzir maiores volumes de leite (Lien et al., 2017). As menos eficientes mantiveram ou diminuíram a quantidade de leite produzida. Os autores apresentaram três comportamentos para propriedades mais eficientes: a possibilidade de menos custos advindos do aumento da escala de produção, mais estabilidade produtiva, garantindo menos variações de produção (com melhor renda ao longo do ano), e produtores mais motivados com a atividade com possibilidades de desenvolvimento futuro da produção leiteira. Esses comportamentos permitem identificar um futuro promissor para propriedades que tenham elevada eficiência produtiva (Lien et al., 2017). Essas considerações estão sumarizadas na Figura 3.

Contudo, uma das limitações da pesquisa é não identificar comportamentos de propriedades menos eficientes, caracterizadas pela manutenção ou diminuição do volume de leite produzido. Caso houvesse tal informação, seria possível aprofundar pesquisas que venham a explorar esses comportamentos e, com disso, propor melhorias que contribuam com o fortalecimento da cadeia produtiva do leite na Noruega.

A obra apresentou uma boa estruturação teórica, composta de detalhada exemplificação dos métodos de pesquisa. Com uma abordagem longitudinal, seria possível um aprofundamento em pesquisas que explorem a capacidade de propriedades leiteiras em lidar com o risco em diferentes cenários, bem como analisar a capacidade dos gestores da atividade leiteira em desenvolver suas práticas gerenciais para lidar com o risco.

\subsection{Percepção e gestão em pequenas propriedades leiteiras}

Foram estudadas 2.500 propriedades leiteiras de pequeno porte na Etiópia, em razão de sua importância para o desenvolvimento local (Gebreegziabher \& Tadesse, 2014). Assim como no Brasil, essas propriedades são limitadas e, muitas vezes, possuem sistemas produtivos pouco eficientes.

A percepção dos produtores rurais sobre os riscos a que a atividade está ou estará exposta é fundamental para o desenvolvimento dessas propriedades. Contudo, existem poucas pesquisas na literatura que explorem esse tema (Gebreegziabher \& Tadesse, 2014). Além disso, quando se consideram estudos sobre a percepção de riscos em pequenas propriedades leiteiras, em países em desenvolvimento, constata-se mais carência de artigos que abordem o tema.

A maioria dos produtores demonstrou conhecimento sobre a necessidade de conhecer riscos e se identificaram como tomadores de decisão nas áreas de mercado, financeira e tecnológica de risco (Gebreegziabher \& Tadesse, 2014). Isso implica dizer que há entendimento dos produtores rurais sobre a necessidade de se ter uma gestão de riscos eficiente e que contribua com o desenvolvimento da atividade leiteira.

O artigo foi estruturado abordando duas temáticas: a percepção dos produtores rurais em relação ao risco e estratégias identificadas por eles utilizadas para lidar com os riscos. A obra analisada não identificou quais eram as estratégias utilizadas para tentar mitigar as variáveis de risco, mas permitiu, por meio da discussão dos resultados, que tal interpretação fosse feita. Por meio da análise fatorial, Gebreegziabher \& Tadesse (2014) definiram as variáveis de mais representatividade 
nos riscos e as estratégias utilizadas pelos produtores de leite da Etiópia. Das 16 variáveis de risco identificadas e das 12 estratégias utilizadas pelos produtores etíopes, Gebreegziabher \& Tadesse (2014) definiram fatores de risco e estratégias utilizadas pelos referidos produtores. A Figura 4 apresenta uma síntese dos resultados encontrados pelos autores da pesquisa.

A pesquisa demonstrou que as práticas de gestão ligadas ao controle higiênico e de doenças estão relacionadas com fatores de risco produtivos e tecnológicos (Figura 4). Foi possível constatar forte predominância de doenças nos rebanhos etíopes, motivo que explica o surgimento de tal fator (Gebreegziabher \& Tadesse, 2014).

As estratégias de gestão adotadas pelos produtores para diversificar a renda apresentaram relação com os fatores financeiros e institucionais (Figura 4). Os fatores financeiros dizem respeito a questões relacionadas a empréstimos e melhora da renda da atividade. Por esse motivo, constata-se que a diversificação da renda contempla práticas de gestão e manutenção de dívidas. Os fatores institucionais se referem à falta de apoio do governo e à limitação da produção leiteira em decorrência da não especialização dos rebanhos. Embora não estejam explícitos na obra, fatores institucionais também podem influenciar nas práticas denominadas rede de mercado, que compreendem a busca por informações de mercado e o marketing cooperativo (Gebreegziabher \& Tadesse, 2014).

Apenas os fatores humanos não apresentaram uma estratégia específica para tentar mitigar seus efeitos sobre a pecuária leiteira da Etiópia (Figura 4). As práticas de diversificação da renda permitem inferir que auxiliam (parcialmente) nesse fator. Contudo, não há evidências de nenhuma prática de gestão que preconize a melhora da saúde das famílias produtoras de leite na Etiópia.

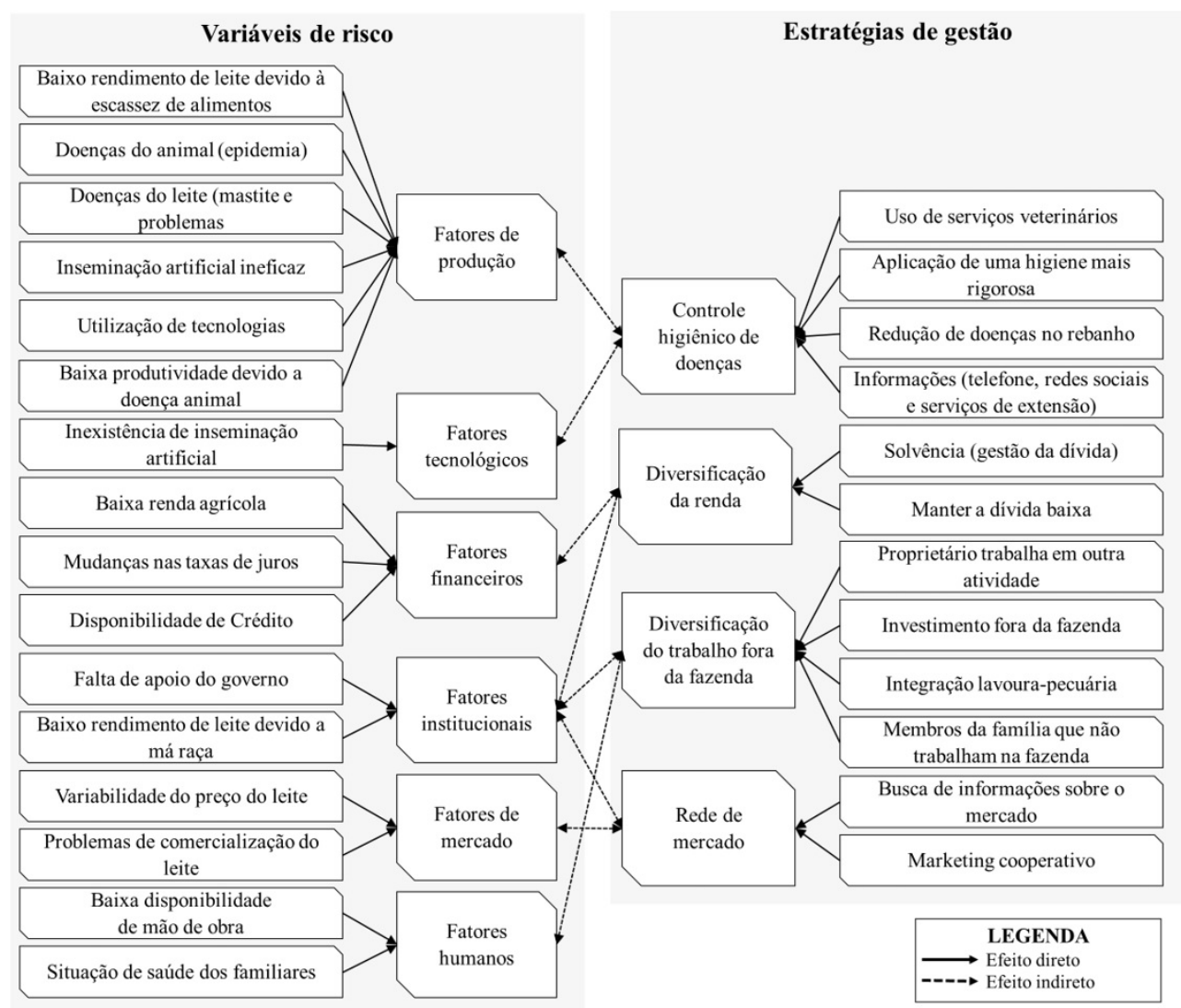

Figura 4. Principais variáveis de risco e estratégias de gestão utilizadas por produtores de leite da Etiópia. Fonte: elaborada pelos autores com base em dados e informações de Gebreegziabher \& Tadesse (2014). 
Com esse artigo, foi possível compreender como é a percepção de pequenos produtores de leite familiar sobre os riscos e as estratégias utilizadas na gestão dos riscos adotadas. A obra, contudo, não apresentou uma relação direta e evidente entre as variáveis de risco e as práticas estratégicas utilizadas na gestão dos riscos nessas propriedades. Novos estudos que permitam identificar, com mais profundidade, quais são as práticas adotadas por produtores familiares no combate ou na prevenção a riscos na atividade leiteira podem contribuir com o fortalecimento desse entendimento.

Por meio da análise das quatro obras (Sauer \& Latacz-Lohmann, 2015; Evink \& Endres, 2017; Lien et al., 2017; Gebreegziabher \& Tadesse, 2014), no próximo tópico serão apresentados um framework de análise e a agenda de pesquisas.

\section{Framework de análise e agenda de pesquisas}

Apenas o artigo de Gebreegziabher \& Tadesse (2014) apresentou dados primários, analisando pequenas propriedades leiteiras de agricultura familiar da Etiópia (Quadro 2). A obra apresentou limitações das propriedades leiteiras, como baixa produção e presença fortemente marcante de doenças de elevado grau de transmissibilidade e/ou impacto econômico na atividade leiteira, como febre aftosa, que estava presente em mais de $14 \%$ das propriedades analisadas.

Por sua vez, as propriedades leiteiras analisadas por Evink \& Endres (2017) apresentaram elevada eficiência produtiva, indicando que um (entre os maiores) risco dessas propriedades é a inflamação das glândulas mamárias (mastite). Por serem consideradas propriedades de elevado porte, os resultados confirmaram a existência de grande capital investido, indicado pelos autores como um componente de oportunidade para o desenvolvimento da pecuária leiteira e risco para a gestão dos custos dessas propriedades. Isso ocorre devido, principalmente, à elevação dos custos com depreciação e remuneração do capital investido. Embora o objeto de estudo desses dois artigos seja antagônico, constatam-se os riscos ocasionados pelas políticas públicas sobre a atividade leiteira, podendo comprometer significativamente os resultados dessas propriedades.

Quadro 2. Resumo das principais características e abordagens de quatro artigos sobre pecuária leiteira

\begin{tabular}{|c|c|c|c|c|}
\hline Item & $\begin{array}{l}\text { Sauer \& Latacz- } \\
\text { Lohmann (2015) }\end{array}$ & $\begin{array}{c}\text { Evink \& Endres } \\
\text { (2017) }\end{array}$ & $\begin{array}{l}\text { Lien et al. } \\
\text { (2017) }\end{array}$ & $\begin{array}{c}\text { Gebreegziabher } \\
\text { \& Tadesse } \\
\text { (2014) }\end{array}$ \\
\hline $\begin{array}{l}\text { Principais } \\
\text { fatores de } \\
\text { eficiência }\end{array}$ & $\begin{array}{l}\text { Investimento, } \\
\text { inovação tecnológica, } \\
\text { educação e nível de } \\
\text { especialização }\end{array}$ & $\begin{array}{c}\text { Inovação tecnológica, } \\
\text { nível de especialização } \\
\text { e sistema de produção } \\
\text { utilizado }\end{array}$ & $\begin{array}{l}\text { Escala de } \\
\text { produção }\end{array}$ & $\begin{array}{l}\text { Produção e } \\
\text { sanidade dos } \\
\text { animais }\end{array}$ \\
\hline $\begin{array}{l}\text { Principais } \\
\text { fatores de } \\
\text { risco }\end{array}$ & $\begin{array}{l}\text { Políticas públicas } \\
\text { e volatilidade do } \\
\text { mercado de leite }\end{array}$ & $\begin{array}{c}\text { Mão de obra } \\
\text { (disponibilidade, políticas } \\
\text { de imigração mais } \\
\text { restritivas e limitação de } \\
\text { pesquisas sobre políticas } \\
\text { públicas), aumento dos } \\
\text { investimentos e piora dos } \\
\text { resultados financeiros da } \\
\text { atividade }\end{array}$ & $\begin{array}{l}\text { Percepção dos } \\
\text { produtores, } \\
\text { habilidades } \\
\text { gerenciais e } \\
\text { capacidade } \\
\text { de tomada de } \\
\text { decisões }\end{array}$ & $\begin{array}{c}\text { Produção, } \\
\text { utilização de } \\
\text { tecnologias, } \\
\text { financeiros, } \\
\text { institucionais, } \\
\text { de mercado e } \\
\text { humanos }\end{array}$ \\
\hline $\begin{array}{c}\text { Perspectivas } \\
\text { para a } \\
\text { pecuária } \\
\text { leiteira }\end{array}$ & $\begin{array}{c}\text { Favoráveis, se } \\
\text { houver eficiência } \\
\text { produtiva }\end{array}$ & $\begin{array}{l}\text { Aumentar a automação } \\
\text { dos processos produtivos }\end{array}$ & $\begin{array}{l}\text { Aumentar a escala } \\
\text { de produção }\end{array}$ & $\begin{array}{l}\text { Melhorar a } \\
\text { eficiência } \\
\text { produtiva para } \\
\text { mitigar riscos }\end{array}$ \\
\hline
\end{tabular}

Fonte: elaborado pelos autores. 
As quatro obras analisadas (Quadro 2) demonstram que as políticas públicas em seus respectivos países não contribuem efetivamente com o fortalecimento da cadeia produtiva do leite, seja por falta de políticas menos restritivas à imigração (nos Estados Unidos), pela ausência ou limitação de subsídios à atividade leiteira (União Europeia), seja por menos preocupação com a saúde pública (Etiópia). Caberia aos governos desses países o desenvolvimento de políticas de médio e longo prazos que contribuam, efetivamente, com o fortalecimento da pecuária leiteira, seja esta de pequeno, médio ou grande porte.

A alta volatilidade dos preços de venda da produção leiteira também é mencionada em todas as obras. No artigo de Evink \& Endres (2017), a volatilidade, embora seja um sério problema nos Estados Unidos, não influenciou o desempenho das propriedades analisadas, visto que o preço médio de venda do leite foi superior ao praticado pelo mercado. Uma explicação seria a elevada quantidade de leite produzida que aumenta o poder de negociação de propriedades maiores, bem como a redução do custo de produção pelo efeito da escala, entendimento corroborado por vários autores (Lopes et al., 2007; Ferrazza et al., 2020; Ferrari \& Braga, 2021).

As quatro obras corroboram com o entendimento sobre a necessidade de gerir riscos para aumentar as perspectivas da atividade. Do mesmo modo, é possível identificar que o aumento da escala de produção e de novas tecnologias é fundamental para melhorar a eficiência da atividade leiteira. Analisando os principais fatores de eficiência e risco para propriedades leiteiras, foi possível desenvolver um esquema (Figura 5) que evidencia os principais fatores de eficiência, risco e perspectivas de propriedades com processos produtivos eficientes.

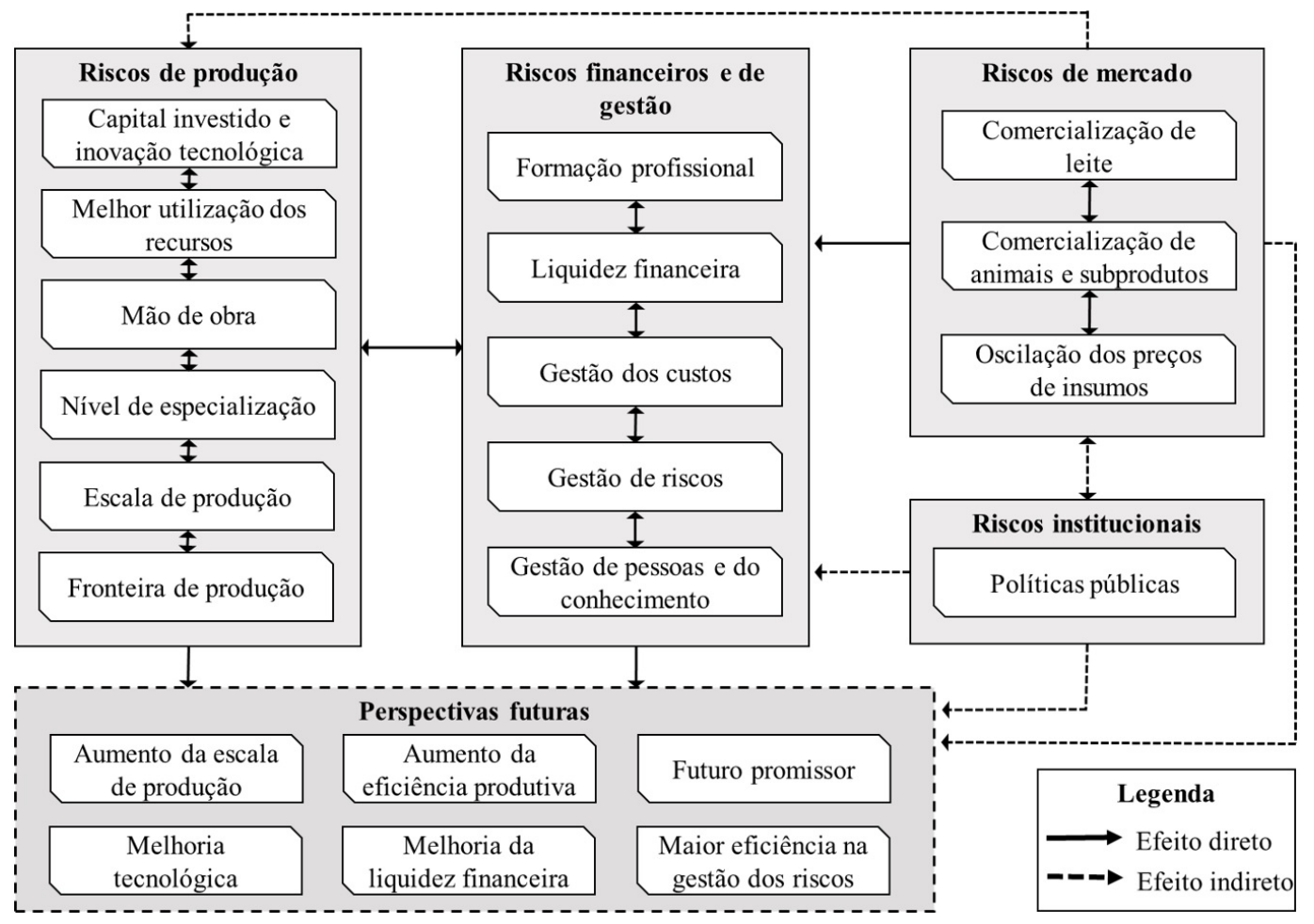

Figura 5. A gestão estratégica da eficiência e dos riscos em propriedades leiteiras. Fonte: elaborada pelos autores com base em dados e informações obtidas na literatura. 
O framework proposto foi desenvolvido com base nos quatro artigos analisados, não refletindo, necessariamente, a realidade brasileira (Figura 5). Para melhor contemplar a realidade da pecuária leiteira no Brasil, a OECD, o Banco Mundial, o MAPA e a Embrapa apresentam os seguintes fatores de risco na agropecuária: de produção ou operacionais, institucionais, de mercado ou de preços e financeiros (Organisation for Economic Co-operation and Development, 2009). Com base nos quatro artigos analisados, optou-se por acrescentar também riscos de gestão, visando conferir mais clareza à Figura 5. Com isso, ficam mais bem evidenciados possíveis fatores de eficiência e risco de processos produtivos do leite no território brasileiro.

Os riscos de produção são todos aqueles ligados às operações de propriedades leiteiras (Buainain \& Silveira, 2017). Investimentos e inovação tecnológica, quando bem implantados na atividade, podem contribuir com a melhora da eficiência produtiva (Figura 5). Caso contrário, podem expor a atividade ao aumento dos riscos de produção. A mão de obra é outro fator produtivo importante para a atividade leiteira, devendo ser qualificada e adaptada para trabalhar com o nível de especialização da propriedade em que está inserida.

Ganhos decorrentes da escala de produção serão sempre decisivos para conferir melhores resultados financeiros. Escalas produtivas, muito próximas da capacidade mínima de produção, podem elevar os riscos do negócio do leite, devido à subutilização dos recursos naturais e produtivos destinados à produção leiteira. Além disso, a (baixa) fronteira de produção pode expor a atividade leiteira a mais riscos se não houver uma boa interação entre o capital investido, a mão de obra e os recursos utilizados na produção. Desse modo, os riscos de produção tendem a diminuir à medida que a eficiência operacional se eleva.

Consideram-se riscos de gestão a formação profissional, a liquidez financeira, a gestão de custos, de riscos, de pessoas e do conhecimento (Figura 5). Esses fatores possuem efeitos diretos (e recíprocos) com os riscos de produção e sofrem efeitos indiretos dos riscos institucionais e diretos do mercado. Propriedades com piores desempenhos operacionais podem comprometer o gerenciamento do negócio do leite, fazendo tais riscos aumentarem. Outros riscos ligados aos níveis táticos e estratégicos de propriedades leiteiras também podem ter seus riscos mensurados nessa categoria.

Riscos de mercado são considerados externos às organizações, englobando questões relacionadas à comercialização e ao preço dos produtos e insumos (Buainain \& Silveira, 2017). Uma vez que os principais produtos de propriedades leiteiras sejam o leite e os animais (Bassotto et al., 2019), é fundamental conhecer os riscos inerentes à comercialização desses produtos, visto que a atividade pode apresentar menos liquidez financeira, quando houver forte redução dos preços de mercado. Instabilidades presentes no mercado podem expor propriedades leiteiras a grandes riscos, comprometendo todo o processo produtivo. Além disso, o aumento dos preços de insumos pode ser outro elemento de risco da atividade leiteira, visto que as oscilações de mercado independem do ambiente interno das propriedades leiteiras (Figura 5).

Na pecuária leiteira, o principal risco institucional identificado corresponde às políticas públicas, que podem influenciar tanto os processos gerenciais quanto as perspectivas do negócio do leite (Figura 5). Além disso, podem influenciar e ser influenciadas pelo mercado, visto que medidas políticas e econômicas podem ser adotadas por diferentes governos, conforme variam os preços dos insumos e produtos, impactando o processo produtivo do leite. Outros riscos institucionais não foram identificados nas quatro publicações analisadas. É possível que a estrutura institucional de propriedades leiteiras ainda seja pouco estudada na literatura. 
Propriedades leiteiras eficientes podem apresentar um futuro promissor, com mais escalas de produção e tecnologicamente mais evoluídas (Figura 5). Como consequência, tem-se a diminuição dos riscos, que pode contribuir com mais estabilidade e previsibilidade da atividade produtiva, garantindo melhores resultados financeiros a longo prazo e, consequentemente, mais liquidez.

Os setores que apresentaram mais necessidades de eficiência para contribuir com a atividade leiteira foram a gestão de riscos, dos custos, de pessoas e do conhecimento, a comercialização do leite, a utilização dos recursos produtivos e naturais, o capital investido e a inovação tecnológica, a escala produtiva, a especialização dos sistemas de produção e a melhora do desempenho financeiro da atividade. Com eficiência, a possibilidade de um futuro mais promissor, com menos riscos, maior escala de produção, mais automação e aumento da produtividade, parece ser mais favorável.

Nenhum dos quatro artigos contemplou os riscos e os possíveis impactos econômicos, sociais e ambientais da utilização dos recursos naturais e do aumento da escala de produção. Também não foi considerado o risco do impacto do crescimento da atividade leiteira sobre a utilização do solo, da água e eventuais riscos ambientais advindos do aumento da produção. Além disso, o aumento do nível de especialização de propriedades leiteiras contribuiu com a melhora da eficiência e redução dos riscos do negócio.

Apesar de ter sido identificada a importância da formação profissional e da busca por conhecimento pelos produtores, os artigos não exploraram como e quais níveis de conhecimento podem impactar a melhora da eficiência e redução dos riscos da atividade leiteira. Visto que sistemas produtivos mais eficientes tendem a ser mais complexos, pesquisas que demonstrem, de forma mais evidente, como esses fatores (conhecimento e formação profissional, eficiência e risco) podem contribuir com o desenvolvimento de pesquisas empíricas sobre o tema são importantes para a melhora da atividade leiteira, que são escassas.

Por fim, destaca-se que a validade de framework proposto para a análise da eficiência e dos riscos da produção leiteira no contexto brasileiro precisa ser testada e validada. Para tanto, serão necessárias a definição e a validação de escalas de mensuração para o conjunto das variáveis que sustentam os seguintes constructos teóricos: riscos de produção, riscos financeiros e de gestão, riscos de mercado, riscos institucionais e perspectivas. Considera-se indispensável a realização dessa etapa qualitativa para estruturar o questionário e aproximar a linguagem do questionário à realidade dos participantes de pesquisas empíricas futuras. Recomendase que seja realizada uma pesquisa qualitativa sobre a percepção de riscos para dar suporte ao desenvolvimento da referida escala de mensuração da eficiência e dos riscos inerentes à atividade leiteira brasileira. Sugere-se também o uso da modelagem de equações estruturais como método para testar possíveis nexos causais entre as variáveis constitutivas do framework proposto. Acredita-se que a adoção dessa abordagem metodológica possa contribuir para a compreensão dos riscos operacionais ou de produção, riscos institucionais, riscos de mercado e riscos financeiros inerentes aos contextos econômico, político, sociocultural e financeiro que particularizam a realidade brasileira.

\section{Conclusões}

O objetivo desta revisão integrativa foi analisar as relações existentes entre eficiência e riscos e propor um framework de análise que integre diferentes pesquisas que abordaram os riscos e a eficiência associados ao negócio leiteiro. 
A análise do conjunto de artigos evidencia que as unidades de produção de leite enfrentam diversos riscos e desafios relacionados à busca de eficiência, pois diferentes fatores influenciam o processo produtivo de leite. Entre esses fatores se destacam as políticas públicas, os investimentos na atividade, a capacidade de inovação tecnológica, a formação e qualificação profissional e o nível de especialização. Essas variáveis são consideradas pela literatura elementos-chave para explicar a eficiência de propriedades leiteiras. Ressalte-se que a obtenção da eficiência está atrelada a racionalização da utilização, expansão da fronteira de produção e preservação da liquidez financeira.

Pode-se afirmar também que a eficiência produtiva depende da estrutura do sistema de produção, do nível de especialização e da inovação tecnológica. Contudo, a busca pela eficiência pode gerar economias de escala e conquista de novos mercados. As propriedades mais eficientes são aquelas que buscam o aumento da escala de produção, a redução de custos e a priorização da qualificação, responsáveis por garantir melhor estabilidade financeira e motivação para enfrentar riscos inerentes à produção de leite. A revisão integrativa apontou também que a produção leiteira envolve diferentes tipos de riscos, ou seja, riscos institucionais, mercadológicos, financeiros, de produção e sanitários, tecnológicos e de gestão de pessoas. Esses diferentes riscos estão associados à dinâmica do ambiente técnico e institucional. Para mitigar os efeitos desses riscos, torna-se necessário estabelecer um processo de gestão que facilite o mapeamento, a análise e a mitigação desses eventos críticos. Esse processo de gestão deve necessariamente envolver a qualificação dos produtores e de sua força de trabalho, pois a revisão integrativa aponta que a eficiência das propriedades leiteiras depende das competências dos produtores, incluindo a percepção dos riscos, habilidades gerenciais e a capacidade em tomar decisões.

Além de apontar uma lacuna de pesquisa sobre o tema eficiência e riscos inerentes à produção de leite, os autores deste artigo propuseram um framework ou modelo de análise da eficiência e risco inerente àquela atividade. Esse modelo integra um conjunto de constructos e variáveis que poderá ser aplicado e validado para o contexto da produção leiteira brasileira. 0 modelo envolve constructos e variáveis relacionados aos riscos institucionais, de produção e mercado, decorrentes da ação humana, financeiros e aponta algumas tendências para o setor.

Acredita-se que esse modelo proposto poderá contribuir para a produção de novos conhecimentos sobre a temática análise de riscos e a eficiência de unidades de produção de leite. Esta pesquisa pode ser especialmente relevante para produtores rurais que tenham interesse em desenvolver práticas que contribuam com a mitigação de riscos intrínsecos ao negócio do leite, visto que o framework pode ser utilizado como checklist de análise da eficiência e dos (eventuais) riscos a que as propriedades leiteiras possam estar expostas.

No que se refere à limitação, a pesquisa não incluiu nenhum artigo que tenha analisado temáticas de eficiência e risco na realidade da pecuária leiteira brasileira. Contudo, análises de artigos internacionais são relevantes. Além disso, não compreendem outros riscos apontados pela literatura como relevantes para o contexto nacional, como riscos financeiros. Sugere-se que novas pesquisas sejam realizadas para analisar como a eficiência e o risco são abordados no contexto brasileiro.

\section{Agradecimentos}

O primeiro autor agradece à Capes pela concessão de uma bolsa de estudos para que esta pesquisa pudesse ser desenvolvida. 


\section{Referências}

Arias, D., Mendes, P., \& Abel, P. (Coords.) (2015). Revisão rápida e integrada da gestão de riscos agropecuários no Brasil: caminhos para uma visão integrada. Brasília: Banco Mundial.

Artuzo, F. D., Foguesatto, C. R., Souza, R., \& Silva, L. X. (2018). Gestão de custos na produção de soja e milho. Revista Brasileira de Gestão de Negócios, 20(2), 279-294. http://dx.doi. org/10.7819/rbgn.v20i2.3192

Bassotto, L. C., Angelocci, M. A., Naves, L. P., \& Putti, F. F. (2019). Relações de comercialização entre compradores e produtores de leite no sul de Minas Gerais. Interações, 20(1), 207-220. http://dx.doi.org/10.20435/inter.v0i0.1671

Brasil. Ministério da Agricultura, Pecuária e Abastecimento - MAPA. (2015). Projeções do agronegócio Brasil 2014/15 a 2024/25: projeções de longo prazo. Brasília/DF: MAPA.

Buainain, A. M., \& Silveira, R. L. (2017). Manual de avaliação de riscos na agropecuária: um guia metodológico. Rio de Janeiro: ENS-CPES.

Dinterman, R., Katchova, A. L., \& Harris, J. M. (2018). Financial stress and farm bankruptcy in US agriculture. Agricultural Finance Review, 78(4), 441-456. http://dx.doi.org/10.1108/AFR05-2017-0030

Douphrate, D. I., Hagevoort, G. R., Nonnenmann, M. W., Kolstrup, C. L., \& Jakob, M. e. (2013). The dairy industry: A brief description of production practices, trends, and famr characteristics around the world. Journal of Agromedicine, 18(1), 187-197. http://dx.doi.org/10.1080/105 9924X.2013.796901

England, J. R., O'Geady, A. P., Fleming, A., Marais, Z., \& Mendham, D. (2019). Trees on farms to support natural capital: an evidence-based review for grazed dairy systems. The Science of the Total Environment, http://dx.doi.org/10.1016/j.scitotenv.2019.135345

Evink, T. L., \& Endres, M. I. (2017). Management, animal health, and economic characteristics of large dairy herds in 4 states in the Upper Midwest of the United States. Journal of Dairy Science, 100(11), 9466-9475. http://dx.doi.org/10.3168/jds.2016-12179

Fassio, L. H., Reis, R. P., Yamaguchi, L. C., \& Reis, A. J. (2005). Custos e shut-down point da atividade leiteira em Minas Gerais. Revista de Economia e Sociologia Rural, 43(4), 759-777. http://dx.doi.org/10.1590/S0103-20032005000400007

Ferrari, M. C. \& Braga, M. J. (2021). A eficiência técnica dos produtores leiteiros no Uruguai. Revista de Economia e Sociologia Rural, 59(2), e221319. http://dx.doi.org/10.1590/18069479.2021.221319

Ferrazza, R. A., Lopes, M. A., Prado, D. G., Lima, R. R., \& Bruhn, F. R. (2020). Association between technical and economic performance indexes and dairy farm profitability. Revista Brasileira de Zootecnia, 49, 1-12. http://dx.doi.org/10.37496/rbz4920180116

Finger, R., Dalhaus, T. A., \& Hirsch, S. (2018). Determinants of downside risk exposure of dairy farms. European Review of Agriculture Economics, 45(4), 641-674. http://dx.doi.org/10.1093/ erae/jby012

Food and Agriculture Organization of the United States Nations - FAO. (2020). Dairy production and products: milk production. Rome: FAO. Recuperado em 9 de abril de 2020, de http:// www.fao.org/dairy-production-products/production/en/

Gebreegziabher, K., \& Tadesse, T. (2014). Risk perception and management in smallholder dairy farming in Tigray, Northen Ethiopia. Journal of Risk Research, 17(3), 367-381. http://dx.doi. org/10.1080/13669877.2013.815648 
Guo, X., Egozcue, M., \& Wong, W. K. (2020). Production Theory under price uncertainty for firms with disappointment aversion. International Journal of Production Research, 59(8), 23922405. https://doi.org/10.1080/00207543.2020.1733699

Instituto Brasileiro de Geografia e Estatística - IBGE. (2020). PIB cresce 1,1\% e fecha 2019 em $R \$ 7,3$ trilhões. Agenda IBGE Notícias. Recuperado em 22 de março de 2021, de https:// agenciadenoticias.ibge.gov.br/agencia-noticias/2012-agencia-de-noticias/noticias/27007pib-cresce-1-1-e-fecha-2019-em-r-7-3-trilhoes

Kivaria, F. M., Noordhuizen, J. P., \& Kapaga, A. M. (2006). Prospects and constraints of smallhhoder dairy husbandry in dar es Salaam Region, Tanzania. Outlook on Agriculture, 35(3), 209-215. http://dx.doi.org/10.5367/000000006778536819

Lien, G., Kumbhakar, S. C., \& Hardaker, J. B. (2017). Accounting for risk in productivity analysis: an application to Norwegian dairy farming. Journal of Productivity Analysis, 47(3), 247-257. http://dx.doi.org/10.1007/s11123-016-0482-2

Lopes, M. A., Reis, E. M., Demeu, F. A., Mesquita, A. A., Rocha, A. G., \& Benedicto, G. C. (2016). Uso de ferramentas de gestão na atividade leiteira: um estudo de caso no sul de Minas Gerais. Revista Científica de Produção Animal, 18(1), 26-44. http://dx.doi.org/10.5935/21764158/rcpa.v18n1p26-44

Lopes, P. F., Reis, R. P., \& Yamaguchi, L. C. (2007). Custos e escala de produção na pecuária leiteira: estudo nos principais estados produtores do Brasil. Revista de Economia e Sociologia Rural, 45(3), 567-590. http://dx.doi.org/10.1590/S0103-20032007000300002

Ogachi, D., Ndege, R., Gaturu, P., \& Zoltan, Z. (2020). Corporate bankruptcy prediction model, a special focus on listed companies of Kenya. Journal of Risk and Finacial Management, 13(3), 47-60. http://dx.doi.org/10.3390/jrfm13030047

Organisation for Economic Co-operation and Development - OECD. (2009). Marketing, risck in agriculture: a holistic approach. Paris: OECD.

Organisation for Economic Co-operation and Development - OECD. (2018). Dairy and dairy products. In Organisation for Economic Co-operation and Development - OECD. OECD-FAO Agricultural Outlook 2018-2027. Paris: OECD.

Örs, A., \& Oğuz, C. (2019). Comparison of economic analysis of dairy farms supported and nonsupported by IPARD program: a case study of Konya Province, Turkey. Custos e Agronegócio Online, 15(2), 192-212.

Perobelli, F. S., Araújo Júnior, I. F. \& Castro, L. S. (2018). As dimensões espaciais da cadeia produtiva do leite em Minas Gerais. Nova Economia, 28(1), 297-337. http://dx.doi.org/10.1590/0103$6351 / 4789$

Reis, L. D., Araújo, R. C., Araújo, J. A., \& Lima, J. R. (2020). Eficiência técnica da produção agrícola dos países da América Latina e do Caribe. Revista de Economia e Sociologia Rural, 58(4), e219416. http://dx.doi.org/10.1590/1806-9479.2020.219416

Santos, C. E., Machado, J. G., Satolo, E. G., \& Valentim, M. L. (2020). Uso da inteligência competitiva no processo de tomada de decisão na pecuária leiteira. Ciência da Informação, 49(2)

Sauer, J., \& Latacz-Lohmann, U. (2015). Investment, technical change and efficiency: empirical evidence from German dairy production. European REview of Agricultural Economics, 42(1), 151-175. http://dx.doi.org/10.1093/erae/jbu015

Scopus. (2020). Scopus. Recuperado em 15 de julho de 2020, de https://www.elsevier.com/ $\mathrm{pt}-\mathrm{br} / \mathrm{solutions} / \mathrm{scopus}$ 
Souza, M. T., Silva, M. D., \& Carvalho, R. d. (2010). Revisão integrativa: o que é e como fazer. Einstein (Sao Paulo, Brazil), 8(1), 102-106.

Thornton, P., Dinesh, D., Cramer, L., Loboguerrero, A., \& Campell, B. (2018). Agriculture in a changing climate: Keeping our cool in the face of the hothouse. Outlook on Agriculture, 47, 283-290. http://dx.doi.org/10.1177/0030727018815332

Torraco, R. J. (2016). Wrinting integrative literature reviews: using the past and present to explore the future. Human Resource Development Review, 15(4), 404-428. http://dx.doi. org/10.1177/1534484316671606

Universidade de São Paulo - USP. Escola Superior de Agricultura Luiz de Queiroz - ESALQ. Centro de Pesquisas Econômicas - CEPEA. (2020). PIB do agronegócio de Minas Gerais. Piracicaba: CEPEA. Recuperado em 22 de março de 2021, de https://www.cepea.esalq.usp. $\mathrm{br} / \mathrm{br} / \mathrm{pib}$-do-agronegocio-de-minas-gerais.aspx

Vilela, D., Ferreira, R. d., Fernandes, E. N., \& Juntolli, F. V. (2016). Pecuária de leite no Brasil: cenários e avanços tecnológicos (1. ed., Vol. 1). Brasília/DF: Embrapa Gado de Leite.

Web of Science. (2020). Web of Science. Recuperado em 15 de julho de 2020, de http:// apps-webofknowledge.ez26.periodicos.capes.gov.br/WOS_GeneralSearch_input. do?product=WOS\&search_mode $=$ GeneralSearch\&SID $=6 \mathrm{~A} \times 7 \mathrm{kR} 5$ XqaNWsBkLmat\&prefere ncesSaved=

Whittemore, R., \& Knafl, K. (2005). The integrative review: updated methodology. Journal of Advanced Nursing, 52(5), 546-553. https://doi.org/10.1111/j.1365-2648.2005.03621.x 